\title{
Fine localisation of the gene for central areolar choroidal dystrophy on chromosome $17 \mathrm{p}$
}

\author{
Anne E Hughes, Andrew J Lotery, Guiliana Silvestri
}

\begin{abstract}
Central areolar choroidal dystrophy (CACD) is a retinal disease which causes progressive profound loss of vision in patients during middle age. The disease is inherited as an autosomal dominant trait and shows genetic heterogeneity. Mutations in the peripherin-RDS gene on chromosome 6 have been reported in affected members of families transmitting the disease. A new locus at chromosome 17 p13 was identified recently by a genome wide linkage search in members of a large Northern Irish family. We now report the refinement of the critical region for this gene to an interval of approximately $5 \mathrm{cM}$ flanked by polymorphic markers D17S1810 and CHLC GATA7B03.

$(\Im$ Med Genet 1998;35:770-772)
\end{abstract}

Keywords: Central areolar choroidal dystrophy; genetic linkage; chromosome $17 p$

Central areolar choroidal dystrophy (CACD) is a rare inherited retinal dystrophy which causes progressive profound loss of vision in patients during their fourth decade. A pathognomonic zone of atrophy affecting retina, retinal pigment epithelium, and choriocapillaris develops in the macular area of the eye. Patients develop absolute central visual scotomas leading to severe visual disability by the seventh decade.

The gene causing CACD in a large Northern Irish family was mapped in $1996^{1}$ by linkage to a cluster of markers at $17 \mathrm{p} 13$. The maximum two point lod score of 4.7 was found at $\theta=0.00$ with D17S796, with a maximum multipoint lod score of 5.65 at D17S938. Analysis of recombination suggested a location in the interval of about $16 \mathrm{cM}$ between D17S5 and D17S804.

\section{Patients and methods}

We have now typed several new markers in this family and have refined the critical CACD gene Revised version accepted for publication 13 February 1998 region. The MLINK and LINKMAP programs of FASTLINK (version 3.0) were used for computerised two point and multipoint analysis of data, assuming autosomal dominant inheritance with a disease allele frequency of 0.0001 and complete penetrance in members of generations I, II, and III. Members of generation IV were assigned as affected or normal on the basis of the presence or absence of electrophysiological abnormalities thought to be indicative of early disease to one of four age related liability classes ranging from $80-95 \%$ likelihood of the assigned disease status. This was because diagnosis is not completely certain in young family members before the onset of pathognomonic features in the fourth decade. Subject IV.13 was the youngest family member assessed (aged 14) and had some abnormal signs of possible disease; however, similar signs were also found recently in her unaffected mother. This girl has inherited the normal haplotype from her affected father at all marker loci in the gene region and it is therefore highly probable that she does not carry the disease allele. She was previously assigned an $80 \%$ risk of carrying the CACD gene, ${ }^{1}$ but has now been excluded from statistical analysis.

\section{Results and discussion}

Two point lod scores between the disease locus and markers (table 1) show a maximum of 5.65 at D17S1832. Haplotypes for markers D17S1876, D17S1810, D17S1832, D17S796, GATA7B03, D17S1844, and D17S1791, spanning an interval of $8 \mathrm{cM}$ of chromosome $17 \mathrm{p} 13$, are shown in fig 1 . The CACD gene region is defined by the position of recombination in subjects III. 3 and II.6. III. 3 is non-recombinant at D17S1832, but recombinant at D17S1810, D17S1876, and more distal markers. The absence of DNA from the parents of II. 6 makes his haplotypes more difficult to analyse. He was previously known to have inherited an allele that was not associated with the disease haplotype at D17S786, and was non-recombinant or uninformative at all other markers tested. The possibility of a mutation in his D17S786 allele was considered; however, he is now found to be recombinant also at GATA7B03, D17S1844, and D17S1791 which flank D17S786. This subject was not fully informative for D17S1353 and the microsatellite at the TP53 locus. The disease gene is therefore restricted to the interval between D17S1810 and GATA7B03, a distance of less than $5 \mathrm{cM}$.

Several inherited eye disorders have recently been mapped to chromosome $17 \mathrm{p}$ (fig 2). They include the autosomal dominant progressive 


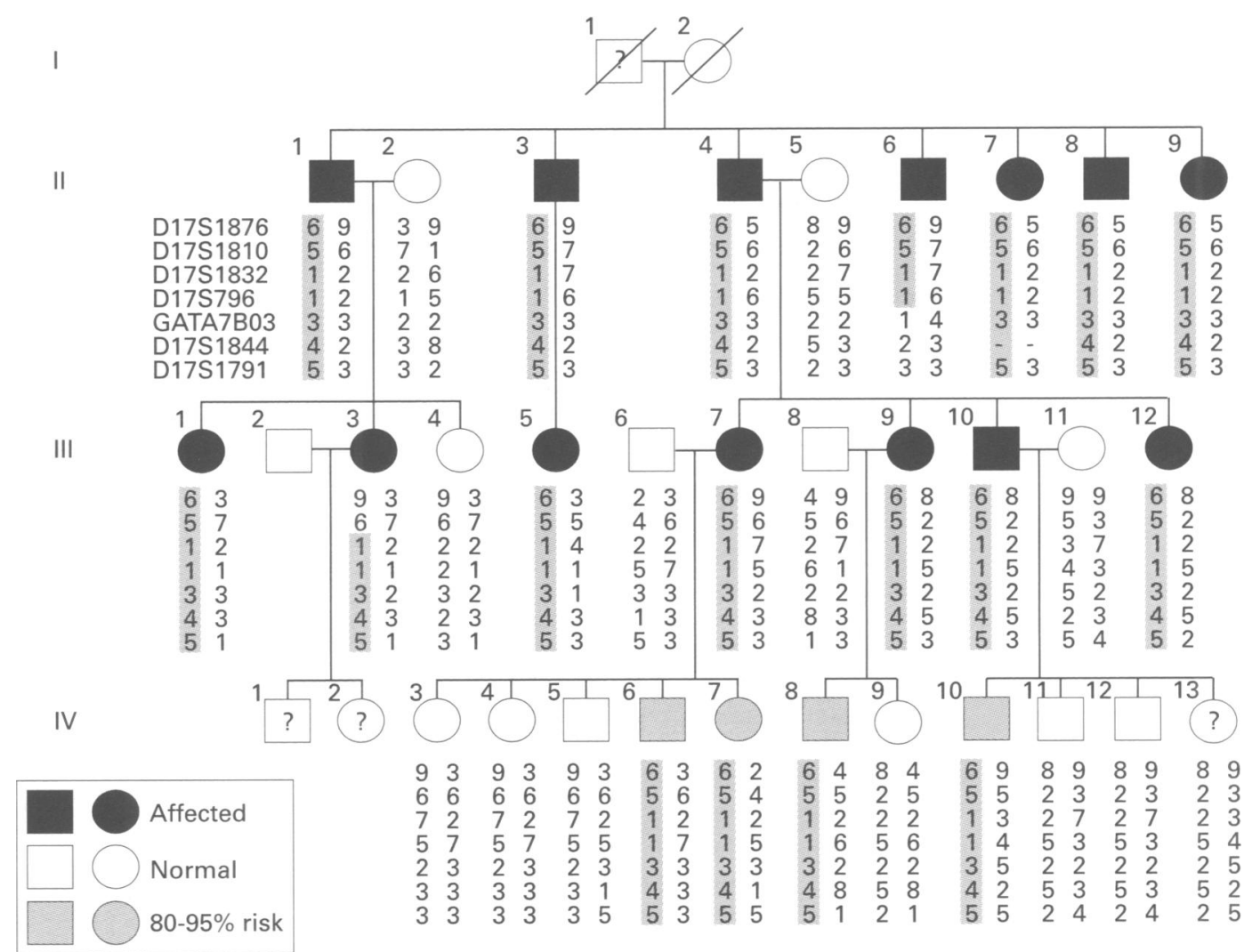

Figure 1 Pedigree of the CACD family showing types for markers D17S1876, D17S1810, D17S1832, D17S796, GATA7B03, D17S1844, and D17S1791 in order from top to bottom. Alleles transmitted by the affected parent are shown on the left of each pair. The haplotype linked to the disease gene is shaded. I.1 and I.2 are of unknown status.

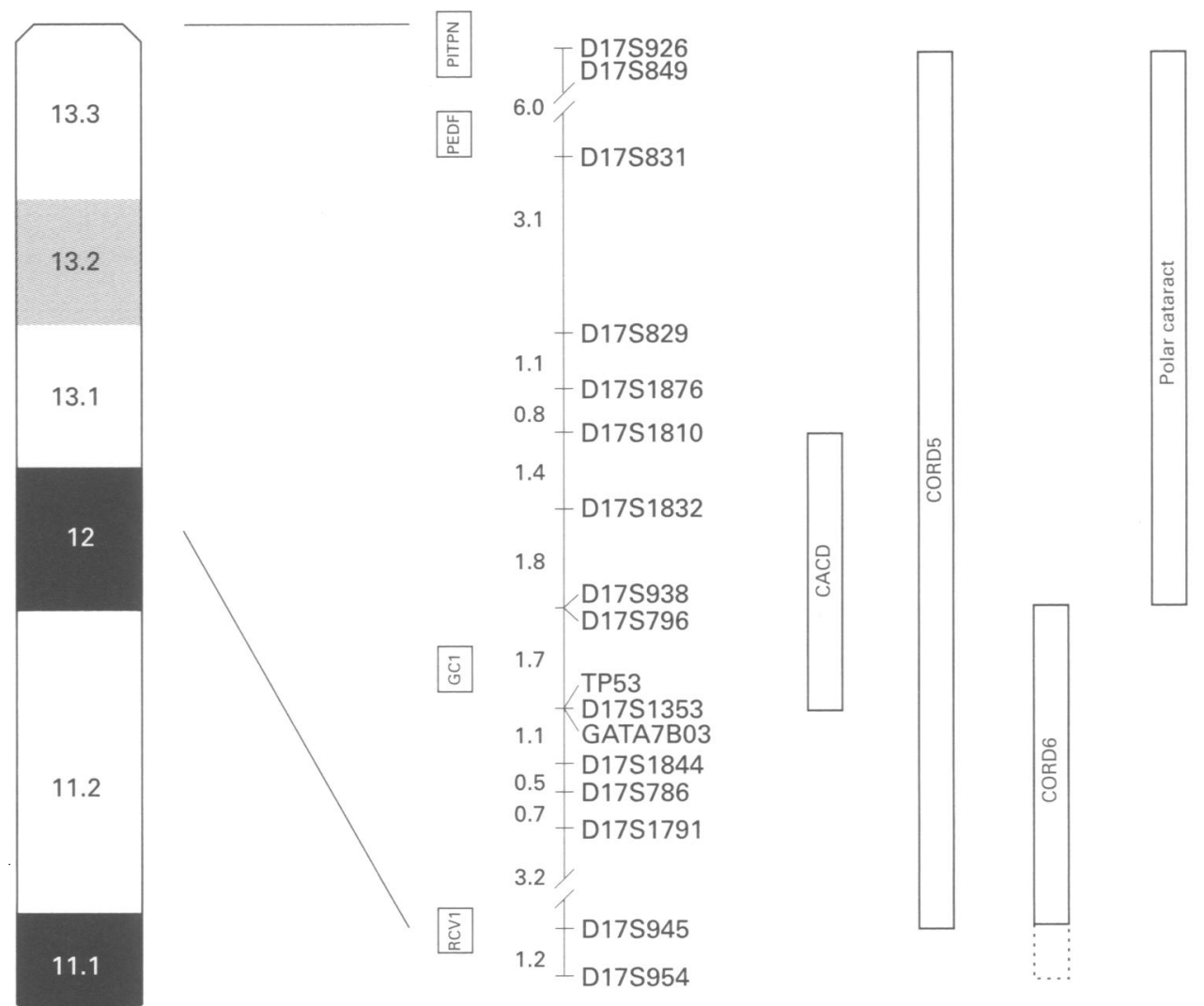

Figure 2 Physical and linkage map of markers on chromosome 17p. Sex averaged distances between markers are shown in $c M$. The locations of candidate genes and linked eye disorders are also indicated.

cone dystrophies $\mathrm{CORD5}^{2}$ and CORD6, ${ }^{3}$ autosomal dominant retinitis pigmentosa (RP13), ${ }^{4}$ autosomal dominant cone degeneration (ADCD), ${ }^{5}$ Leber's congenital amaurosis
(LCA) ${ }^{6}$ and anterior polar cataract. ${ }^{7}$ It is interesting to speculate whether the same gene could be involved in CACD, CORD5, and CORD6. The CORD5 family described shows 
central choroidal atrophy which is also a typical feature of CACD and these disorders have a similar age of onset. Affected members of the CORD6 family have an earlier age of onset, but full clinical details have yet to be reported. If mutations within a single gene are responsible for these retinal dystrophies, the search for the gene can be focused on the $1.7 \mathrm{cM}$ interval between D17S938/D17S796 and the TP53/ D17S1353/GATA7B03 cluster.

LCA maps in many families to the interval between D17S938 and D17S1353 ${ }^{\circ}$ and in 1996 mutations in the retinal guanylate cyclase (GC1) gene were identified in affected subjects. GC1 lies within the CACD region. The entire coding region of the gene was sequenced in affected and normal members of the CACD family, but no mutations were found (data not shown). This was not unexpected because both LCA and the autosomal dominant cone degeneration which also maps to $17 \mathrm{p}$ have more diverse fundal appearances ${ }^{9}$ and are therefore unlikely to be caused by the gene which is responsible for CACD.

Several other candidate genes for retinal disorders map to $17 \mathrm{p}$ (fig 2). These include phosphatidylinositol transfer protein (PITPN), pigment epithelium derived factor (PEDF), recoverin (RCV1), and $\beta$-arrestin 2 (ARRB2). The PITPN gene has homology with the Drosophila retinal degeneration B gene $(r d g B)$ which is responsible for light enhanced retinal degeneration. ${ }^{10}$ The PEDF gene product possesses both neurotrophic and neuronal survival activities ${ }^{11}$ and recoverin mediates the recovery of the dark current after photoactivation in the retina. ${ }^{12}$ These genes, however, map outside the CACD region. The ARRB2 gene is expressed in the retina and is thought to be involved in regulation of receptor binding to a $G$ protein. It maps to $17 \mathrm{p} 13,{ }^{13}$ but has not been finely localised. Regarding the physical position of ARRB2, the Genebridge 4 radiation hybrid map suggests that the gene probably lies distal to the CACD region, but it has not been placed precisely with respect to the polymorphic genetic mapping markers.

The molecular basis of most of the retinal disease genes which have been mapped recently to chromosome $17 \mathrm{p}$ remains to be established. Several interesting candidate genes are expressed and have important roles in the retina, but are not yet associated with any retinal phenotypes. Advances in molecular genetics have provided the tools which should allow the genes responsible for these diseases to be found. At present it is unclear whether CACD and the cone rod dystrophies CORD5 and CORD6 are caused by mutations in one or a cluster of genes. Reducing the region of the CACD gene will assist its identification and will also enable the genetic influence of this locus to be assessed in age related macular degeneration and related macular dystrophies.

1 Lotery AJ, Ennis K, Silvestri G, et al. Localisation of a gene for central areolar choroidal dystrophy to chromosome 17p. Hum Mol Genet 1996;5:705-8.

2 Balciuniene J, Johansson K, Sandgren O, Wachtmeister I Holmgren G, Forsman K. A gene for autosomal-dominan progressive cone dystrophy (CORD5) maps to chromosome 17p12-p13. Genomics 1995;30:281-6.

3 Kelsell RE, Evans K, Gregory CY, Moore AT, Bird AC, Hunt DM. Localisation of a gene for dominant cone rod dystrophy (CORD6) to chromosome 17p. Hum Mol Gene dystrophy (COR

4 Greenberg J, Goliath RG, Beighton P, Ramesar R. A new locus for autosomal dominant retinitis pigmentosa on the short arm of chromosome 17. Hum Mol Genet 1994;3:91518 .

5 Small KW, Mullen L, Syrquin M, Gehrs K, Inana G. Autosomal-dominant cone degeneration maps to chromosome 17p. Am ₹ Hum Genet Suppl 1995;57:A203.

6 Perrault I, Rozet JM, Calvas P, et al. Retinal-specific guanylate-cyclase gene-mutations in Leber's congenital guanylate-cyclase gene-mutations in

7 Berry V, Ionides ACW, Moore AT, Plant C, Bhattacharya SS, Shiels A. A locus for autosomal dominant anterior polar cataract on chromosome 17p. Hum Mol Genet 1996; 5:415-19.

8 Camuzat A, Rozet JM, Dollfus $\mathrm{H}$, et al. Evidence of geneticheterogeneity of Leber's congenital amaurosis (LCA) and mapping of LCA1 to chromosome 17p13. Hum Genet mapping of LCA1

9 Joshi AR, Mullen L, Small KW. The retina: genetic studies of several retinopathies located on the short arm of chromosome 17. Curr Opin Neurol 1997;10:31-5.

10 Vihtelic TS, Goebl M, Milligan S, O'Tousa JE, Hyde DR. Localization of Drosophila retinal degeneration B, a membrane-associated phosphatidylinositol transfer protein. $¥$ Cell Biol 1993;122:1013-22.

11 Tombran-Tink J, Shivaram SM, Chader GJ, Johnson LV, Bok D. Expression, secretion, and age-related downregulaBok D. Expression, secretion, and age-related downregulation of pigment epithelium-derived factor, a serpin
neurotrophic activity. $\mathcal{F}$ Neurosci 1995;15:4992-5003.

12 Gray-Keller MP, Polans AS, Palczewski K, Detwiler PB. The effect of recoverin-like calcium-binding proteins on the photoresponse of retinal rods. Neuron 1993;10:523-31.

13 Calabrese G, Sallese M, Stornaiuolo A, Stuppia L, Palka G, De Blasi A. Chromosome mapping of the human arrestin (SAG), beta-arrestin 2 (ARRB2), and beta-adrenergic receptor kinase 2 (ADRBK2) genes. Genomics 1994;23: 286-8. 